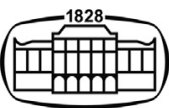

AKADÉMIAI KIADÓ

\title{
The role of social factors in the successful ageing - Systematic review
}

\section{J. TAKÁCS ${ }^{1 *}$ (๑) and C. NYAKAS ${ }^{2}$}

\section{Developments in Health Sciences}

4 (2021) 1, 11-20

DOI:

$10.1556 / 2066.2021 .00044$

(c) 2021 The Author(s)

\section{REVIEW ARTICLE}

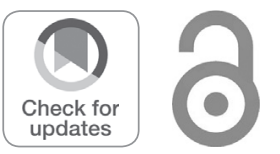

${ }^{*}$ Corresponding author. Department of Social Sciences, Faculty of Health Sciences, Semmelweis University, Vas utca 17, H-1088, Budapest, Hungary. E-mail: takacs.johanna@se-etk.hu; spss.stat@gmail.com

\author{
${ }^{1}$ Department of Social Sciences, Faculty of Health Sciences, Semmelweis University, Budapest, \\ Hungary \\ ${ }^{2}$ Department of Morphology and Physiology, Faculty of Health Sciences, Semmelweis University, \\ Budapest, Hungary
}

Received: June 12, 2021 Revised manuscript received: July 5, 2021 • Accepted: September 10, 2021 Published online: November 18, 2021

\begin{abstract}
Purpose: Ageing is a complex phenomenon that should be studied in a multidisciplinary approach examining the biological, psychological, and social determinants in it. There is a lack of understanding of how social factors contribute to a better and healthier way of ageing. Based on previous studies social factors have a more essential role in ageing successfully. These factors have a significant influence on mental and physical health as well. The present review aims to collect the most researched social factors related to successful ageing and to examine the associations revealed between social factors and successful ageing. Materials/Methods: We conducted a systematic review by the guidelines of the PRISMA statements. We examined the studies included by using a qualitative synthesis to identify the most important social factors and their role in successful ageing. Results: In total, 18 original articles published in English between 2015 and 2020 were included in the review. The examined social factors related to successful ageing can be classified into four categories: Social engagement/participation, Social support, Social integration/network, and Socio-demographic/Socioeconomic factors. Social factors are modifiable and protective determinants, they could eliminate the negative effects of psychological factors while modifying the effects of physical determinants of ageing at the same time. Conclusions: Our results have implications for future studies, as successful ageing should be examined in a multidimensional way. They should provide further evidence for the mediating/moderating importance of social factors which also have relevance in practice. Social factors could provide a quality life for years to come.
\end{abstract}

\section{KEYWORDS}

systematic review, successful ageing, social factors, mediation, moderation

\section{INTRODUCTION}

In modern societies, the average life expectancy is dramatically increasing. In Hungary, the life expectancy at birth was 75.52 years in 2019 [1]. Furthermore, the older adult population has been exceeding the childhood population for years (ageing indicator $=139.5$ ) [1]. The ageing trend in society makes it particularly important to examine how to achieve successful ageing. Rowe and Kahn were the first to differentiate usual and successful ageing [2, 3]: "low probability of disease and (disease-related) disability, high physical and mental functioning, and active engagement with life". However, there has not been a consensus definition of successful ageing yet [4-6]. There are several terms of successful ageing such as healthy, active, and productive ageing, as well as ageing well [6]. Although biomedical aspects are still more accentuated, now ageing is considered a multidimensional concept $[7,8]$; ageing studies increasingly use social, mental, spiritual, and environmental components [9].

To examine the effect of social factors in successful ageing, we need to first conceptualise exactly what we mean by social factors that are used in diverse ways across studies. These social factors, human social relationships are embedded in the proximal and distal social 
environment. Considering the distal social environment there are social-structural conditions, the so-called "macrosocial factors/context" [10] such as socioeconomic factors, culture, politics, and social changes. The proximal factors of social relationships are social networks (social integration), social support, and social engagement (social involvement, social participation).

\section{Social networks (social integration)}

According to Merriam-Webster Dictionary, the social network is "a network of individuals (such as friends, acquaintances, and co-workers) connected by interpersonal relationships". One's social networks can be described by their characteristics such as size, density, homogeneity etc. and by the characteristics of network ties such as frequency and duration of social contacts [10].

\section{Social support}

Social support refers to "the provision of assistance or comfort to others, typically to help them cope with biological, psychological, and social stressors" [11]. Social supports are multifaceted $[12,13]$ and can be divided into four dimensions: emotional, tangible (instrumental), informational, and companionship support [14]. Researchers generally distinguish perceived social support and received social support. Perceived social support means one's subjective perceptions of aid available from others and received social support which is aid provided by others [15]. Social support can be measured by structural and functional support; assessing social integration and functions which are provided by the members of social networks (i.e. perceived and received social support) [16].

\section{Social engagement (social involvement, social participation)}

There is not a consistent and precise meaning of the concept of social engagement [17]. It refers to social involvement in a community of society and participation in social activities, building social and emotional connections with people. At the same time, studies highlight the distinction from social networks or social support. Researchers measure this term in wide variety of ways such as the number of social activities or interactions with others, time spent in social activities, the number of relatives and friends, and volunteering.

Social capital comprising of individual and collective social resources as well as structural and subjective aspects may be a protective factor for some diseases [18]. Thus, social capital is also a crucial element of successful ageing $[19,20]$. It is a well-known fact that social relationships including social integration and social support are prospectively associated with all-cause mortality [21-24], even a causal association can be demonstrated [25]. Throughout human life, these social factors play an important role in establishing and maintaining health [26-28], quality of life, and well-being [29-33]. Individual differences in well-being can be partially explained by social factors [34].
Although the importance of the associations of social relationships and health has been repeatedly demonstrated, the different pathways by which social factors affect health are not well elucidated. There are various mechanisms hypothesised such as stress buffering $[35,36]$, which assumes that social support affects mental health and wellbeing on a basis of an "overall beneficial effect" (main effect model) and on a basis of a protective process from negative influences of stressful life events (buffering model). Based on Berkman's conceptual model there is a cascading causal process from social resources to social networks which "provide opportunities" for social support, social engagement, social influence, person-to-person contact, and access to resources and material goods. These psychosocial mechanisms impact health via health behavioural, psychological, and physiological pathways [10]. Besides, we can hypothesise pathways via role modelling, social control of health behaviours, sense of control or mastery, belonging and companionship, etc. [13].

In sum, we do not fully understand yet how different social factors influence successful ageing. There is consistent evidence indicating the influence of primary social factors in health outcomes and mortality such as gender, race, income, and education [37-40]. At the same time, other social factors which are related to being actively and socially engaged in life are less examined than biomedical or psychological factors in achieving a better and healthier way of ageing [4, 41]. Some studies have examined so-called psychosocial factors but, in these cases, social factors are considered as covariates or confounding factors rather than independent factors in successful ageing.

The present review aims to collect the most researched social factors in recent years related to successful ageing. Furthermore, we examine the associations revealed between social factors and ageing outcomes.

\section{MATERIALS AND METHODS}

The present systematic review follows the PRISMA guidelines, but it is non-preregistered [42]. We conducted the literature search between November 2019 and June 2020. In line with our inclusion criteria, we included quantitative original articles published in English between 2015 and 2020. The systematic search was based on PubMed, Medline, Scopus, OVID, and Web of Science databases. We used the combination of the following search terms: ag*ing, healthy/ active ag*ing, successful ag*ing, social factor*, psychosocial factor*.

We identified 1,639 records in databases through term searches. Of these, 218 records met the inclusion criteria based on Title, Abstract, and Keywords. After duplicates $(n=197)$ and further non-relevant studies which examined 'frailty and falls' $(n=5)$ were removed, we screened 192 records. Of these, 127 records were excluded (review articles, meta-analytic studies, book chapters, letters/opinions). We assessed for eligibility 65 full-text original articles, and we excluded further 42 articles that did not study successful 
ageing as the outcome of interest, and five articles that used social factors as covariates. A total of 18 full-text original articles were included in the present review. For the study selection process, see Fig. 1.

Most studies included are longitudinal studies on ageing (13 studies). Four studies are cross-sectional analyses of a longitudinal study on ageing, and one was a cross-sectional study. The included studies cover areas of three continents (Europe, Asia, and North America) (Fig. 2). The samples of most studies come from the population of older adults (aged older than 55 years). Characteristics of the selected studies are presented in Table 1 .

\section{RESULTS}

\section{Social factors in successful ageing}

Different aspects of social life were presented in the selected studies. We classified the social factors into four categories: 1) Social engagement and participation, 2) Social support, 3) Social integration and network, 4) Sociodemographic, socioeconomic factors.
Social engagement and participation. The most studied aspects of social life were social engagement and participation. They examined the influence of cultural engagement [III, IX], regular church attendance [XVI], social volunteering [XIII], and community group membership [X]. They also evaluate the quality of participation in social, cognitive, or leisure activities [VI, XII, XVIII].

Social support. The second most studied social factor was social support which is one of the support resources besides material aid, emotional support, or companionship [II, IV, VI, XIII, XIV, XV]. Social support usually comes from family, relatives, or friends. In this case, it is essential to examine the availability of and satisfaction with social support as well [II].

Social integration and network. The studies on social integration and network examined 1) the structural dimension of social relationships such as frequency of contact with friends and relatives [I], the number of social roles [VIII]; 2) degree and efficiency of one's social network [XI], 3) characteristics of broader social environment, viz. neighbourhood social cohesion [VII], and neighbourhood disorder such as vandalism, rubbish, crime, etc. [XVII].

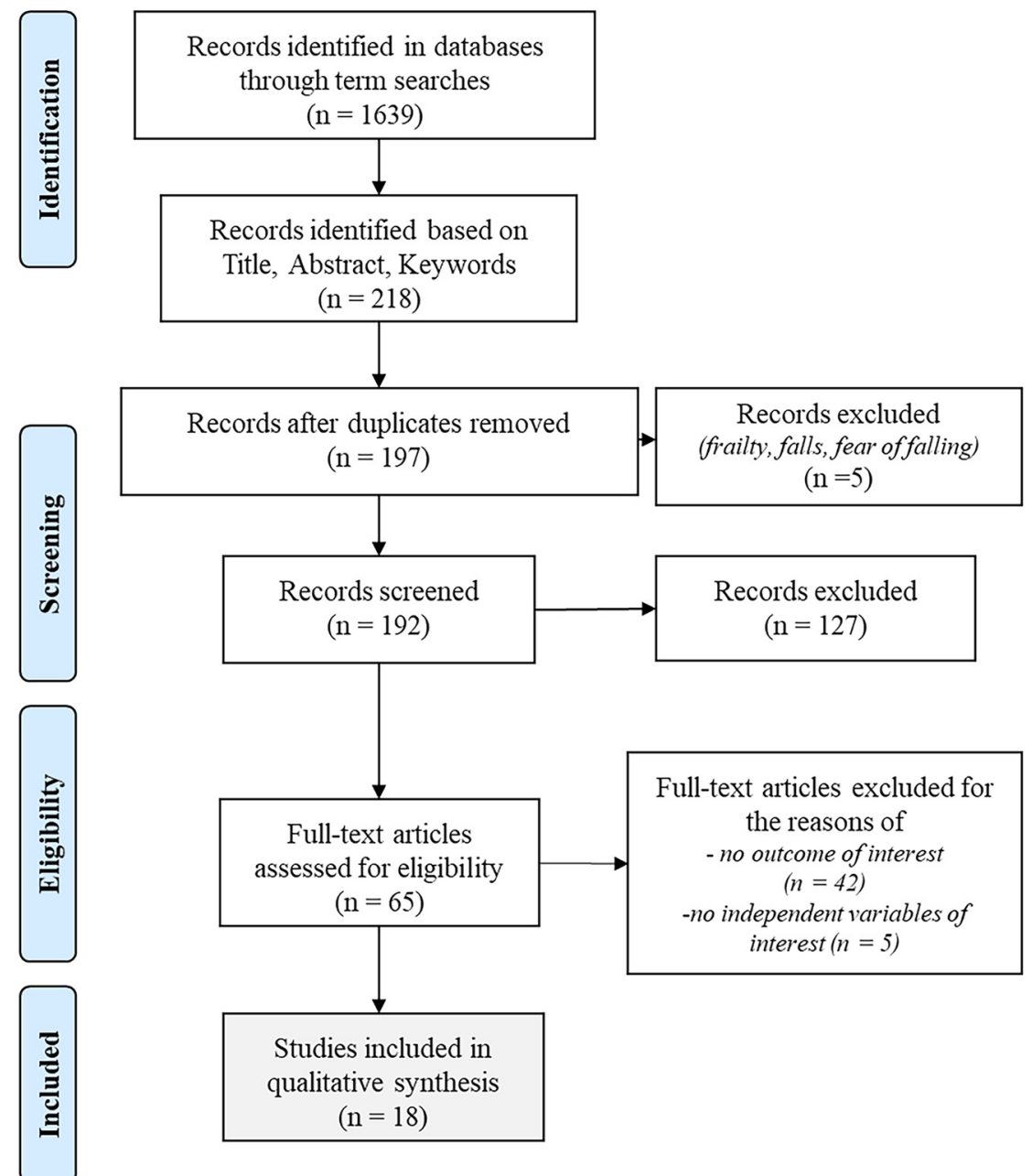

Fig. 1. Flow chart of the review process 


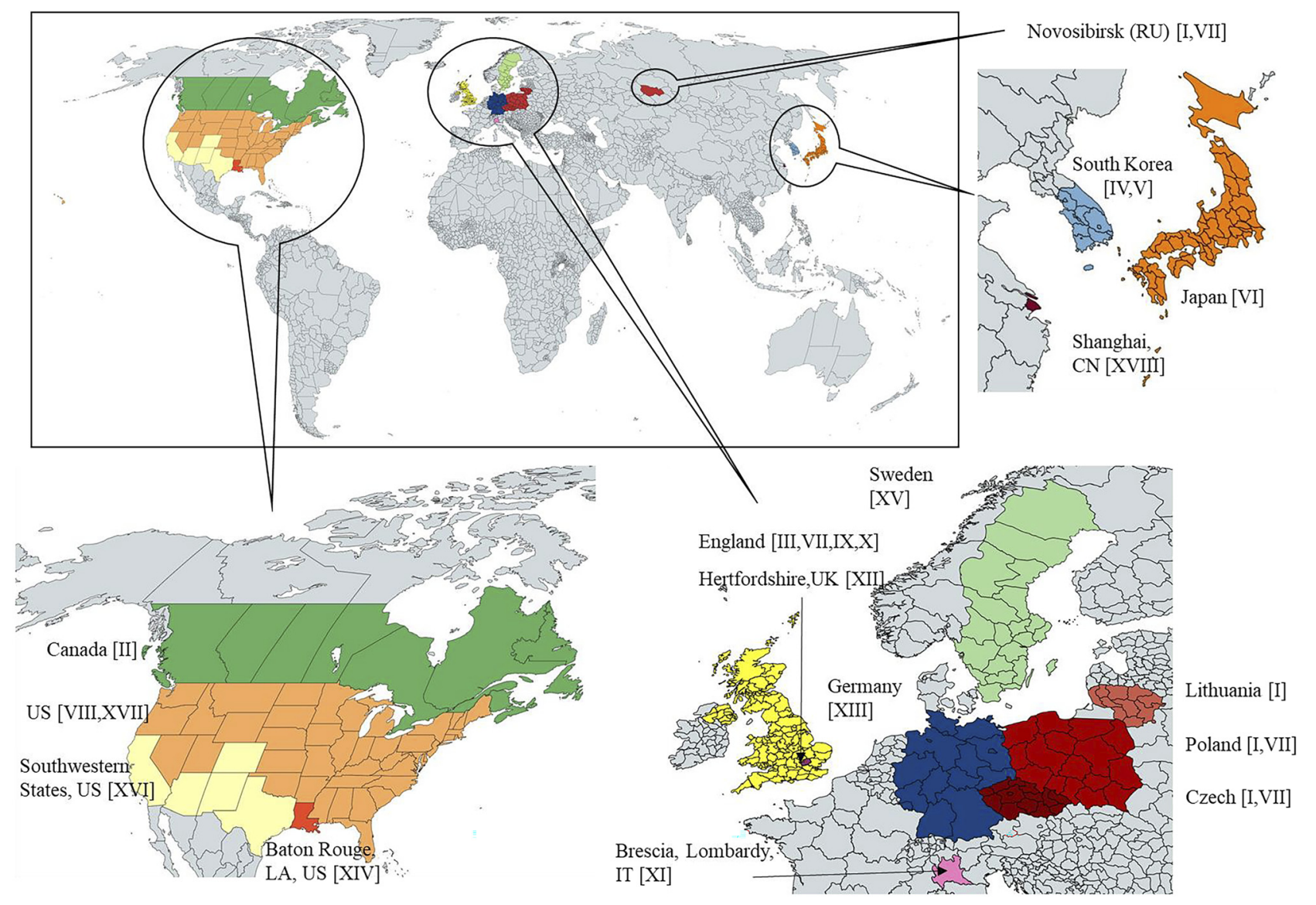

Fig. 2. Places of the selected studies.

Note. The figure was created by mapchart.net

Sociodemographic and socioeconomic factors. Some selected studies examined sociodemographic and socioeconomic characteristics concerning successful ageing (not as covariates). These factors include education, income, residential areas, commercial health insurance [V], as well as gender and marital status [XVI].

\section{Associations of social factors and successful ageing}

Social engagement and participation. Social engagement and participation have a protective role in cognition. The cultural engagement was associated with a lower risk of developing dementia in older age [III]. Regular church attendance has an association with a slower decline in cognitive functions [XVI]. These social factors also have a protective role for late-life well-being. More diverse social relationships are associated with a higher level of life satisfaction [VI] and membership in different community groups or religious group membership is related to enhanced wellbeing $[\mathrm{X}]$. The effect of participation in social activities can be particularly important mainly for elderly women and for the old-old to maintain a higher level of psychological wellbeing [XVIII]. Finally, socially engaged volunteering is associated with higher perceived control [XIII]. Sense of control is crucial to maintaining positive and stable subjective well-being, and it starts to decline after midlife. Furthermore, social engagement and participation have a protective role against the development of chronic conditions such as the development of widespread pain [IX] and decline in diet quality [XII].

Social support. Social support from family, relatives, friends, or significant others has a protective role for cognition, wellbeing, and play an important role in the prevention of the development of chronic conditions. Social support availability as a functional dimension of social relationships has a positive association with the memory domain of cognitive function [II]. Social support entails a slighter decline in late-life wellbeing [VI] and it has a direct effect on successful ageing outcomes such as autonomous life, self-completion orientation, active involvement in life, satisfaction with one's children, self-acceptance, and acceptance of others [IV]. Besides, social support satisfaction is associated with self-reported health [XIV]. Finally, in the case of social support, the level and sources of social support may adjust its effects. For instance, less social support is associated with stronger perceived control [XIII] indicating that social support at a higher level may relate to a higher state of need and thus decrease perceived control. Social support can predict hospitalisation risk, more support from friends is associated with a lower risk of hospitalisation, and more support from 
Table 1. Characteristics of the selected studies

\begin{tabular}{|c|c|c|c|c|c|}
\hline ID & Authors & Date & Design & Sample size & $\begin{array}{c}\text { Sample age range } \\
(\mathrm{M}, \mathrm{SD})\end{array}$ \\
\hline [I] & Luna E, Ruiz M, Malyutina S, et al. & 2020 & longitudinal (HAPIEE) & 6,106 & $(62.5,6.2)$ \\
\hline [II] & Oremus M, Tyas SL, Maxwell CJ, et al. & 2020 & $\begin{array}{c}\text { cross-sectional (CLSA, } \\
\text { baseline) }\end{array}$ & 21,241 & $45-85$ \\
\hline [III] & Fancourt D, Steptoe A, Cadar D. & 2019 & longitudinal (ELSA) & 9,550 & $50+, 50-99(65.2,9.2)$ \\
\hline [IV] & Han SY, Ko Y. & 2019 & cross-sectional & 201 & $65+(73.9,6.1)$ \\
\hline$[\mathrm{V}]$ & Kim EM, Kim SH, Lee GH, et al. & 2019 & longitudinal (KLoSA) & 10,162 & $45-79(61.7,11.1)$ \\
\hline [VI] & Nakagawa T, Hülür G. & 2019 & longitudinal (NSJE) & 1,119 & (79.2, 7.7 age at death) \\
\hline [VII] & Ruiz M, Malyutina S, Pajak 7A, et al. & 2019 & $\begin{array}{l}\text { longitudinal (ELSA-EN, } \\
\text { HAPIEE-CZ, -PO, -RU) }\end{array}$ & 26,081 & $\begin{array}{c}64.3 \text { (ELSA-EN), } 58.4 \\
\text { (HAPIEE-CZ), } 57.6 \\
(-P O), 58.2(-\mathrm{RU})\end{array}$ \\
\hline [VIII] & Crittenden CN, Murphy MLM, Cohen S. & 2018 & longitudinal (HRS) & 4,224 & $52-94(67.4,9.2)$ \\
\hline$[\mathrm{IX}]$ & Fancourt D, Steptoe A. a & 2018 & longitudinal (ELSA) & 2,631 & $50+(63.0,7.7)$ \\
\hline$[\mathrm{X}]$ & Fancourt D, Steptoe A. b & 2018 & longitudinal (ELSA) & 2,548 & $55+$ \\
\hline$[\mathrm{XI}]$ & Bianchetti L, Squazzoni F, Casnici N, et al. & 2017 & $\begin{array}{c}\text { cross-sectional } \\
\text { ('ANZIANI IN-RETE') }\end{array}$ & 200 & $65+(77.7,7.6)$ \\
\hline$[\mathrm{XII}]$ & Bloom I, Edwards M, Jameson K, et al. & 2017 & $\begin{array}{c}\text { longitudinal cohort } \\
\text { (HCS) }\end{array}$ & 1,910 & $59-73(66)$ \\
\hline [XIII] & Drewelies J, Wagner J, Tesch-Römer C, et al. & 2017 & longitudinal (DEAS) & 10,081 & $40-85(60.2,12.2)$ \\
\hline [XIV] & Cherry KE, Brown JS, Kim S, et al. & 2016 & cross-sectional (LHAS) & $\begin{array}{l}771 \text { (360 older and } \\
\text { oldest-old) }\end{array}$ & $\begin{array}{c}\text { 65-84 (older; } 74.4,5.2 \text { ), } \\
\text { 85-101 (oldest-old; } 91.2 \text {, } \\
2.4 \text { ) }\end{array}$ \\
\hline$[\mathrm{XV}]$ & Hallgren J, Fransson EI, Kåreholt I, et al. & 2016 & longitudinal (SATSA) & 772 & $46-103(69.7,11.1)$ \\
\hline$[\mathrm{XVI}]$ & Howrey BT, Raji MA, Masel M, et al. & 2015 & longitudinal (H-EPESE) & 2,767 & $65+(73.2,6.5)$ \\
\hline$[\mathrm{XVII}]$ & Latham K, Williams MM. & 2015 & longitudinal (HRS) & 5,922 & $(69.8,9.9)$ \\
\hline [XVIII] & Zhang W, Feng Q, Liu L, et al. & 2015 & $\begin{array}{l}\text { cross-sectional (Survey } \\
\text { of the Shanghai Elderly } \\
\text { Life and Opinion) }\end{array}$ & 3,418 & $(69.9,10.3)$ \\
\hline
\end{tabular}

Note. CLSA: Canadian Longitudinal Study on Aging, DEAS: Deutscher Alterssurvey [German Ageing Survey], ELSA: English Longitudinal Study of Ageing, HAPIEE: Health, Alcohol and Psychosocial factors In Eastern Europe, HCS: Hertfordshire Cohort Study, H-EPESE: Hispanic Established Populations for Epidemiologic Study of the Elderly, HRS: Health and Retirement Study, KLoSA: Korean Longitudinal Study of Aging, LHAS: Louisiana Healthy Aging Study, NSJE: National Survey of Japanese Elderly, SATSA: Swedish Adoption/Twin Study of Aging.

relatives is associated with an increased risk of hospitalisation [XV]. Support from friends may encourage healthy behaviours and support from relatives may encourage seeking hospital care especially when health deteriorates.

Social integration and network. More contact with friends and relatives (network efficiency) and more intense relationships between unrelated contacts (network variety) improve quality of life [I] and are associated with a lower number of chronic diseases [XI]. Furthermore, the number of social roles is associated with less age-related loss of lung function [VIII], which is an important marker of health and longevity. Finally, societal disruption such as low neighbourhood cohesion and increased neighbourhood disorder is associated with a lower level of well-being, increasing depressive symptoms [VII] and lower odds of recovery from mobility limitation [XVII].

Sociodemographic, socioeconomic factors. Socioeconomic factors such as education, income, residential areas, commercial health insurance are associated with increased mortality risk $[\mathrm{V}]$ independently negative mental health, and they are often prioritised over mental health. Being a woman, having a high school education, being married had a significant positive impact on cognition and cognitive change in later life [XVI].

The selected studies examined mostly direct effects of social factors to successful ageing after taking health-related variables and a broad range of sociodemographic/socioeconomic factors into account. Indirect effects (moderating and/or mediating effects) of social factors were not assumed. At the same time, it is important to underline that social factors interact with psychological factors and these factors are in a reciprocal relationship. It can be experienced many times that the effects of social factors to successful ageing are mediated through mental health, sometimes over and above health behavioural pathways (Fig. 3).

\section{DISCUSSION}

In recent years, the concept of successful ageing has become an important term to describe a better and healthier way of ageing. Although it is regarded in a multidimensional way, the measured outcomes of 'ageing well' [43, 44] represent mainly biomedical aspects of successful ageing. Most of the selected studies measured successful ageing by the domains 

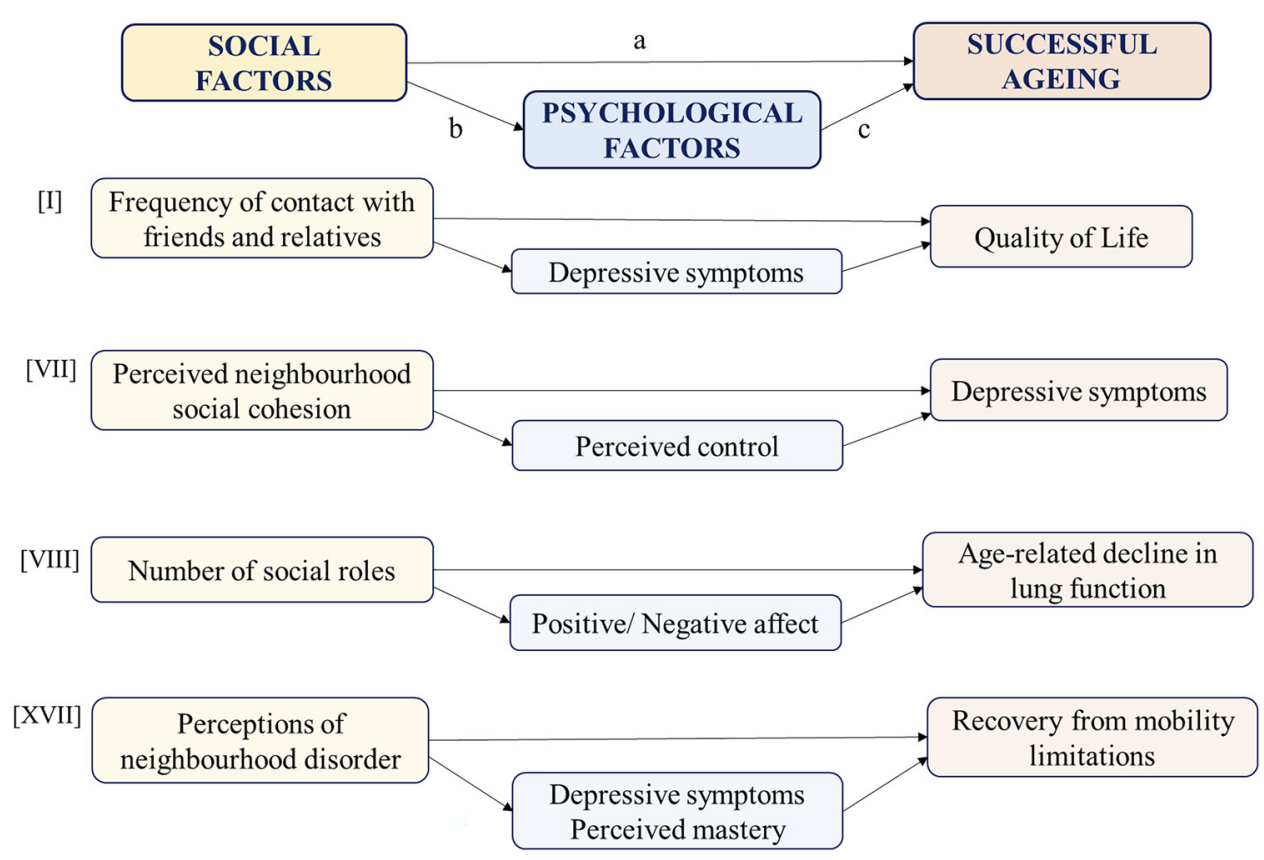

Fig. 3. Relationships of social factors and successful ageing mediated by psychological processes. Note. a: direct effects, $\mathrm{b}+\mathrm{c}$ : indirect (mediating) effects

of physical and cognitive functioning $[6,8]$. Physical functioning was measured by avoiding disease and disabilities such as the risk of development of chronic pain [IX] and hospitalisation $[\mathrm{XV}]$, the number of chronic diseases [XI], insufficient lung function [VIII], decline in diet quality [XII], the odds of recovery from mobility limitation [XVII], selfreported health [XIV, XVIII], and mortality risk [V]. Cognitive functioning was measured by memory [II, XVI], reasoning problems [XVI], and the development of dementia [III]. In addition to physical and cognitive functioning, some studies defined successful ageing by measuring well-being [I, VI, X, XVIII] and different aspects of mental health. They examined the level of autonomous life, selfcompletion orientation, positive life participation, satisfaction with one's offsprings, self-acceptance, acceptance of others [IV], prevalence of depressive symptoms [VII], and perceived control [XIII] as the indicators of a proper psychological adaptation in older adults.

Based on the selected studies, we classified the most examined social factors into four categories such as 1) Social engagement and participation, 2) Social support, 3) Social integration and network, and 4) Sociodemographic, socioeconomic factors. Associations revealed were mostly direct effects of social factors on successful ageing outcomes. Some associations were mediated by psychological processes and some were also operated via health behavioural pathways. At the same time, indirect effects (moderating/mediating) of social factors were missing; however, they can be assumed based on the previous studies.

In the present review, in line with the results of previous studies, we also demonstrated that the various components of social integration, the individual's involvement in a wide variety of social relationships, and the quality of the social relationship affect physical, cognitive, and mental health outcomes, as well as the overall social integration of older adults $[10,13,45,46]$.

Social support is one of the well-documented factors influencing physical health outcomes [47-49]. Social support is crucial in chronic illness self-management behaviours [50] and one's adherence to medical treatment [51, 52], as well as health outcomes $[22,53]$. Social support also plays an important role in coping with stressful events (stress buffering hypothesis) $[35,36]$, thus it is associated with late-life well-being.

Social relationships including social networks, participation, and support benefit older adults' global cognitive functioning and working memory [54] and can play role in decreasing the risk of dementia [55]. Greater network diversity is associated with a lower risk for disease and death $[25,47]$. Poor social relationships have a negative impact on mental health [56], especially on depression outcomes [57]. In depressive disorders, poorer perceived social support is associated with poorer symptoms, recovery, and functioning [58].

Social engagement (social involvement and participation) is associated with specific health conditions such as cardiovascular disease, recurrent myocardial infarction, atherosclerosis, autonomic dysregulation, and high blood pressure, [59-61] and it may also be a protective factor against cognitive decline at older ages [62].

It is important to note that different social factors are interrelated, for example, the number of personal social contacts related to the adequacy of instrumental and emotional support [63]. The relationships of social factors and health are very complex, as a recent study demonstrated that the various social supports, i.e. emotional, tangible, 
informational support and companionship, have a heterogeneous effect on physical and mental health at different ages [64]. The associations between social relationships and physical/mental health are also influenced by other factors such as gender, age, religion, marital status, health behaviours, and socioeconomic status. [65].

In sum, the associations revealed in the present study demonstrated that social engagement and participation, social support, social network have a protective role for cognition, well-being, and decreased risk of developing chronic conditions in older adults. Social relationships and social integration may increase one's sense of identity, predictability, stability, purpose, meaning, belonging, security, and self-worth $[14,36,66]$, as well as they may increase emotional regulation providing more positive effects and thus can limit the intensity and duration of negative affective states [36]. The social factors examined play a crucial role in adapting to ageing. These social factors may help older people to maximise their well-being in the context of physical decline through an adaptive process using the socalled selection-optimization-compensation (SOC) strategies [67], which ensure adapting to deficits of ageing, selecting activities suitable for older adults, optimising possessed skills, and compensating for losses [67, 68].

\section{Limitations}

The present review sought to follow the PRISMA guidelines, but it is non-preregistered. There are some limitations such as selection bias. Systematic reviews require access to a wide range of databases and peer-reviewed journals, our study relies on a relatively limited number of databases for the identification of potentially eligible studies. There is also language and locating bias including studies published in English between November 2019 and June 2020. There is inevitable subjectivity in the screening process even though we tried to use explicit inclusion criteria and give a defined process of synthesis. Finally, we could not provide a list of excluded studies.

\section{CONCLUSIONS}

In sum, the selected studies underline the fact that social resources are important components of successful ageing. One of the most important aspects of social relationships is that they are modifiable risk and protective factors. We must take the distal and proximal social environment into account to establish and maintain better physical and somatic health. Older people commonly spend more time in the neighbourhood and they tend to stay in their residence $[69,70]$. Thus, interventions and social services should be focused on the interpersonal and community spheres of older adults' lives. This is especially important when we also consider the fact that social support from family, relatives, and friends may be weakened, and this may lead to social isolation. It is important to note that we have to manage several demographic factors that may be barriers to participation in cognitive, leisure, and social activities or joining community groups. Based on the present review, we believe that there is an opportunity to support a better quality of life, late-life well-being with more active promotion of social engagement, and participation in the ageing population.

Authors' contribution: $\mathrm{CN}$ conceived the idea and supervised the selection, screening, and writing processes. JT: made the review process and wrote the manuscript with support from $\mathrm{CN}$. All authors read and approved the final manuscript.

\section{Ethical approval: NA.}

Conflicts of interest: The authors declare no conflict of interest.

\section{ACKNOWLEDGEMENTS}

The study was supported by the Higher Education Institutional Excellence Program at Semmelweis University and the National Bionics Program ED_17-1-2017-0009.

\section{REFERENCES}

1. Hungarian Central Statistical Office. [Internet]. Budapest: KSH; [cited 2021 July 1]. Available from: https://www.ksh.hu/populationand-vital-events.

2. Rowe JW, Kahn RL. Human aging: usual and successful. Science 1987;237:143-9. https://doi.org/10.1126/science.3299702.

3. Rowe JW, Kahn RL. Successful aging. Gerontologist 1997;37: 433-40. https://doi.org/10.1093/geront/37.4.433.

4. Cosco TD, Prina AM, Perales J, Stephan BC, Brayne C. Operational definitions of successful aging: a systematic review. Int Psychogeriatr 2014;26:373-81. https://doi.org/10.1017/S1041610213 002287.

5. Kok AA, Aartsen MJ, Deeg DJ, Huisman M. Capturing the diversity of successful aging: an operational definition based on 16-year trajectories of functioning. Gerontologist 2017;57:240-51. https:// doi.org/10.1093/geront/gnv127.

6. Fernandez-Ballesteros R. The concept of successful aging and related terms. In: Fernandez-Ballesteros R, Benetos A, Robine JM, editors. The Cambridge handbook of successful aging. NewYork, NY: Cambridge University Press; 2019. p. 6-22.

7. Calasanti T. Combating ageism: how successful is successful aging? Gerontologist 2016;56:1093-101. https://doi.org/10.1093/geront/ gnv076.

8. Urtamo A, Jyväkorpi SK, Strandberg TE. Definitions of successful ageing: a brief review of a multidimensional concept. Acta Biomed 2019;90:359-63. https://doi.org/10.23750/abm.v90i2.8376.

9. Kim SH, Park S. A meta-analysis of the correlates of successful aging in older adults. Res Aging 2017;39:657-77. https://doi.org/10. 1177/0164027516656040.

10. Berkman LF, Glass T, Brissette I, Seeman TE. From social integration to health: Durkheim in the new millennium. Soc Sci Med 2000;51:843-57. https://doi.org/10.1016/s0277-9536(00)00065-4. 
11. VandenBos GR. APA dictionary of psychology. 2th ed. Washington, DC: American Psychological Association; 2007.

12. Zimet GD, Powell SS, Farley GK, Werkman S, Berkoff KA. Psychometric characteristics of the multidimensional scale of perceived social support. J Pers Assess 1990;55:610-7. https://doi.org/10.1080/ 00223891.

13. Thoits PA. Mechanisms linking social ties and support to physical and mental health. J Health Soc Behav 2011;52:145-61. https://doi. org/10.1177/0022146510395592.

14. Wills TA. Supportive functions of interpersonal relationships. In: Cohen S, Syme L, editors. Social support and health. Orlando, FL: Academic Press; 1985. p. 61-82.

15. Kent de Grey R, Uchino BN, Trettevik R, Cronan S, Hogan J. Social support. Oxford Bibliographies in Psychology [Internet]. Oxford, UK: Oxford University Press; 2018 Jan [cited 2021 Jan 11]. Available from: https://doi. org/10.1093/OBO/9780199828340-0204.

16. Wills TA. Social support. In: Blechman EA, Brownell KD, editors. Behavioral medicine and women: a comprehensive handbook. New York, NY: Guilford Press; 1998. p. 118-28.

17. Mendes de Leon CF. Social engagement and successful aging. Eur J Ageing 2005;2:64-6. https://doi.org/10.1007/s10433-005-0020-y.

18. Rodgers J, Valuev AV, Hswen Y, Subramanian SV. Social capital and physical health: an updated review of the literature for 20072018. Soc Sci Med 2019;236:112360. https://doi.org/10.1016/j. socscimed.2019.112360.

19. Arezzo MF, Guidici C. The effect of social capital on health among European older adults: an instrumental variable approach. Soc Indic Res 2017;134:153-66. https://doi.org/10.1007/s11205-016-1411-5.

20. Boen F, Pelssers J, Scheerder J, et al. Does social capital benefit older adults' health and well-being? The mediating role of physical activity. J Aging Health 2020;32:688-97. https://doi.org/10.1177/ 0898264319848638.

21. Smith KP, Christakis NA. Social networks and health. Annu Rev Sociol 2008;34:405-29. https://doi.org/10.1146/annurev.soc.34. 040507.134601.

22. Holt-Lunstad J, Smith TB, Layton JB. Social relationships and mortality risk: a meta-analytic review. Plos Med 2010;7:e1000316. https://doi.org/10.1371/journal.pmed.1000316.

23. Kreibig SD, Whooley MA, Gross JJ. Social integration and mortality in patients with coronary heart disease: findings from the Heart and Soul Study. Psychosom Med 2014;76:659-68. https://doi.org/10. 1097/PSY.0000000000000100.

24. Tan J, Wang Y. Social integration, social support, and all-cause, cardiovascular disease and cause-specific mortality: a prospective cohort study. Int J Environ Res Public Health 2019;16:1498. https:// doi.org/10.3390/ijerph16091498.

25. House JS, Landis KR, Umberson D. Social relationships and health. Science 1988;241:540-5. https://doi.org/10.1126/science.3399889.

26. Cohen S. Social relationships and health. Am Psychol 2004;59: 676-84. https://doi.org/10.1037/0003-066X.59.8.676.

27. Valtorta NK, Kanaan M, Gilbody S, Ronzi S, Hanratty B. Loneliness and social isolation as risk factors for coronary heart disease and stroke: systematic review and meta-analysis of longitudinal observational studies. Heart 2016;102:1009-16. https://doi.org/10.1136/ heartjnl-2015-308790.

28. Gronewold J, Kropp R, Lehmann N, et al. Association of social relationships with incident cardiovascular events and all-cause mortality. Heart 2020;106:1317-23. https://doi.org/10.1136/ heartjnl-2019-316250.

29. Myers DG. Close relationships and quality of life. In: Kahneman D, Diener E, Schwarz N, editors. Well-being: the foundations of hedonic psychology. New York, NY: Russell Sage Foundation; 1999. p. 374-91.

30. Myers DG. The funds, friends, and faith of happy people. Am Psychol 2000;55:56-67. https://doi.org/10.1037//0003-066x.55.1. 56.

31. Brannan D, Biswas-Diener R, Mohr CD, Mortazavi S, Stein N. Friends and family: a cross-cultural investigation of social support and subjective well-being among college students. J Posit Psychol 2013;8:65-75.

32. Sandstrom GM, Dunn EW. Social interactions and well-being: the surprising power of weak ties. Pers Soc Psychol Bull 2014;40: 910-22. https://doi.org/10.1177/0146167214529799.

33. Sun J, Harris K, Vazire S. Is well-being associated with the quantity and quality of social interactions? J Pers Soc Psychol 2020;119: 1478-96. https://doi.org/10.1037/pspp0000272.

34. Jivraj S, Nazroo J, Vanhoutte B, Chandola T. Aging and subjective well-being in later life. J Gerontol B Psychol Sci Soc Sci 2014;69: 930-41. https://doi.org/10.1093/geronb/gbu006.

35. Cohen S, Wills TA, Stress WTA. Stress, social support, and the buffering hypothesis. Psychol Bull 1985;98:310-57. https://doi.org/ 10.1037/0033-2909.98.2.310.

36. Cohen S. Psychosocial models of the role of social support in the etiology of physical disease. Health Psychol 1988;7:269-97. https:// doi.org/10.1037//0278-6133.7.3.269.

37. Kim J, Durden E. Socioeconomic status and age trajectories of health. Soc Sci Med 2007;65:2489-502. https://doi.org/10.1016/j. socscimed.2007.07.022.

38. Crimmins EM, Kim JK, Seeman TE. Poverty and biological risk: the earlier "aging" of the poor. J Gerontol A Biol Sci Med Sci 2009;64: 286-92. https://doi.org/10.1093/gerona/gln010.

39. Lynch SM. Race, socioeconomic status, and health in life-course perspective: introduction to the special issue. Res Aging 2008;30: $127-36$.

40. Wallace SP. Equity and social determinants of health among older adults. Generations: J Am Soc Aging 2014;38:6-11.

41. Kleineidam L, Thoma MV, Maercker A, et al. What is successful aging? A psychometric validation study of different construct definitions. Gerontologist 2019;59:738-48. https://doi.org/10.1093/ geront/gny083.

42. Moher D, Liberati A, Tetzlaff J, Altman DG; PRISMA Group. Preferred reporting items for systematic reviews and meta-analyses: the PRISMA statement. PloS Med 2009;6:e1000097. https://doi.org/ 10.1371/journal.pmed.1000097.

43. Fernández-Ballesteros R, García LF, Abarca D, et al. Lay concept of aging well: cross-cultural comparisons. J Am Geriatr Soc 2008;56: 950-2. https://doi.org/10.1111/j.1532-5415.2008.01654.x.

44. Fernández-Ballesteros R, Robine JM, Walker A, Kalache A. Active aging: a global goal. Curr Gerontol Geriatr Res 2013;2013:298012. https://doi.org/10.1155/2013/298012.

45. Stephens C, Noone J, Alpass F. Upstream and downstream correlates of older people's engagement in social networks: what are their effects on health over time? Int J Aging Hum Dev 2014;78:149-69. https://doi.org/10.2190/AG.78.2.d. 
46. Umberson D, Montez JK. Social relationships and health: a flashpoint for health policy. J Health Soc Behav 2010;51:S54-66. https:// doi.org/10.1177/0022146510383501.

47. Uchino, B. Social support and physical health: understanding the health Consequences of relationships. New Haven, CT: Yale University Press; 2004.

48. Uchino BN, Bowen K, Carlisle M, Birmingham W. Psychological pathways linking social support to health outcomes: a visit with the "ghosts" of research past, present, and future. Soc Sci Med 2012;74: 949-57. https://doi.org/10.1016/j.socscimed.2011.11.023.

49. Barth J, Schneider S, von Känel R. Lack of social support in the etiology and the prognosis of coronary heart disease: a systematic review and meta-analysis. Psychosom Med 2010;72:229-38. https:// doi.org/10.1097/PSY.0b013e3181d01611.

50. Gallant MP. The influence of social support on chronic illness selfmanagement: a review and directions for research. Health Educ Behav 2003;30:170-95. https://doi.org/10.1177/1090198102251030.

51. DiMatteo MR. Social support and patient adherence to medical treatment: a meta-analysis. Health Psychol 2004;23:207-18. https:// doi.org/10.1037/0278-6133.23.2.207.

52. Valtorta NK, Moore DC, Barron L, Stow D, Hanratty B. Older adults' social relationships and health care utilization: a systematic review. Am J Public Health 2018;108:e1-10. https://doi.org/10. 2105/AJPH.2017.304256.

53. Holt-Lunstad J. Why social relationships are important for physical health: a systems approach to understanding and modifying risk and protection. Annu Rev Psychol 2018;69:437-58. https://doi.org/ 10.1146/annurev-psych-122216-011902.

54. Kelly ME, Duff H, Kelly S, et al. The impact of social activities, social networks, social support and social relationships on the cognitive functioning of healthy older adults: a systematic review. Syst Rev 2017;6:259. https://doi.org/10.1186/s13643-017-0632-2.

55. Kuiper JS, Zuidersma M, Oude Voshaar RC, et al. Social relationships and risk of dementia: a systematic review and meta-analysis of longitudinal cohort studies. Ageing Res Rev 2015;22:39-57. https:// doi.org/10.1016/j.arr.2015.04.006.

56. Kawachi I, Berkman LF. Social ties and mental health. J Urban Health 2001;78:458-67. https://doi.org/10.1093/jurban/78.3.458.

57. Santini ZI, Koyanagi A, Tyrovolas S, Mason C, Haro JM. The association between social relationships and depression: a systematic review. J Affect Disord 2015;175:53-65. https://doi.org/10.1016/j. jad.2014.12.049.

58. Wang J, Mann F, Lloyd-Evans B, Ma R, Johnson S. Associations between loneliness and perceived social support and outcomes of mental health problems: a systematic review. BMC Psychiatry 2018; 18:156. https://doi.org/10.1186/s12888-018-1736-5.

59. Ertel KA, Glymour MM, Berkman LF. Social networks and health: a life course perspective integrating observational and experimental evidence. J Soc Pers Relat 2009;26:73-92.

60. Everson-Rose SA, Lewis TT. Psychosocial factors and cardiovascular diseases. Annu Rev Public Health 2005;26:469-500. https:// doi.org/10.1146/annurev.publhealth.26.021304.144542.

61. Uchino BN, Way BM. Integrative pathways linking close family ties to health: a neurochemical perspective. Am Psychol 2017;72: 590-600. https://doi.org/10.1037/amp0000049.

62. Seeman TE, Lusignolo TM, Albert M, Berkman L. Social relationships, social support, and patterns of cognitive aging in healthy, high-functioning older adults: MacArthur studies of successful aging. Health Psychol 2001;20:243-55. https://doi.org/10.1037// 0278-6133.20.4.243.

63. Seeman TE, Berkman LF. Structural characteristics of social networks and their relationship with social support in the elderly: who provides support. Soc Sci Med 1988;26:737-49. https://doi.org/10. 1016/0277-9536(88)90065-2.

64. Yang F, Jiang Y. Heterogeneous influences of social support on physical and mental health: evidence from China. Int J Environ Res Public Health 2020;17:6838. https://doi.org/10.3390/ ijerph17186838.

65. Zhang YJ, Jin YL, Zhu TT. The health effects of individual characteristics and environmental factors in China: evidence from the hierarchical linear model. J Clean Prod 2018;194:554-63.

66. Thoits PA. Multiple identities and psychological well-being: a reformulation and test of the social isolation hypothesis. Am Sociol Rev 1983;48:174-87.

67. Baltes PB, Baltes MM. Psychological perspectives on successful aging: the model of selective optimization with compensation. In: Baltes PB, Baltes MM, editors. Successful aging: perspectives from the behavioral sciences. New York: Cambridge University Press; 1990. p. 1-34.

68. Baltes MM, Carstensen LL. The process of positive aging. Aging Soc 1996;16:397-422.

69. Yen IH, Michael YL, Perdue L. Neighborhood environment in studies of health of older adults: a systematic review. Am J Prev Med 2009;37:455-63. https://doi.org/10.1016/j.amepre.2009.06.022.

70. Yen IH, Shim JK, Martinez AD, Barker JC. Older people and social connectedness: how place and activities keep people engaged. J Aging Res 2012;2012:139523. https://doi.org/10.1155/ 2012/139523.

\section{LIST OF SELECTED ARTICLES}

I. Luna E, Ruiz M, Malyutina S, et al. The prospective association between frequency of contact with friends and relatives and quality of life in older adults from Central and Eastern Europe. Soc Psychiatry Psychiatr Epidemiol 2020;55:1001-10. https://doi.org/10. 1007/s00127-020-01834-8.

II. Oremus M, Tyas SL, Maxwell CJ, Konnert C, O’Connell ME, Law J. Social support availability is positively associated with memory in persons aged 45-85 years: a cross-sectional analysis of the Canadian Longitudinal Study on Aging. Arch Gerontol Geriatr 2020;86: 103962. https://doi.org/10.1016/j.archger.2019.103962.

III. Fancourt D, Steptoe A, Cadar D. Community engagement and dementia risk: time-to-event analyses from a national cohort study. J Epidemiol Community Health 2020;74:71-7. https://doi.org/10. 1136/jech-2019-213029.

IV. Han SY, Ko Y. A structural equation model of successful aging in Korean older women: using selection-optimization-compensation (SOC) strategies. J Women Aging 2019;33:84-99. https://doi.org/ 10.1080/08952841.2019.1681883.

V. Kim EM, Kim SH, Lee GH, Kim YA. Socioeconomic vulnerability, mental health, and their combined effects on all-cause mortality in Koreans, over 45 Years: analysis of Korean longitudinal study of aging from 2006 to 2014. Korean J Fam Med 2019;40:227-34. https://doi.org/10.4082/kjfm.18.0137. 
VI. Nakagawa T, Hülür G. Social integration and terminal decline in life satisfaction among older Japanese. J Gerontol B Psychol Sci Soc Sci 2020;75:2122-31. https://doi.org/10.1093/geronb/gbz059.

VII. Ruiz M, Malyutina S, Pajak A, Kozela M, Kubinova R, Bobak M. Congruent relations between perceived neighbourhood social cohesion and depressive symptoms among older European adults: an East-West analysis. Soc Sci Med 2019;237:112454. https://doi. org/10.1016/j.socscimed.2019.112454.

VIII. Crittenden CN, Murphy MLM, Cohen S. Social integration and age-related decline in lung function. Health Psychol 2018;37: 472-80. https://doi.org/10.1037/hea0000592.

IX. Fancourt D, Steptoe A. Physical and psychosocial factors in the prevention of chronic pain in older age. J Pain 2018;19:1385-91. https://doi.org/10.1016/j.jpain.2018.06.001.

X. Fancourt D, Steptoe A. Community group membership and multidimensional subjective well-being in older age. J Epidemiol Community Health 2018;72:376-82. https://doi.org/10.1136/jech2017-210260.

XI. Bianchetti L, Squazzoni F, Casnici N, et al. Social networks and health status in the elderly: the 'ANZIANI IN-RETE' populationbased study. Aging Clin Exp Res 2017;29:1173-9. https://doi.org/ 10.1007/s40520-017-0726-7.

XII. Bloom I, Edwards M, Jameson KA, et al. Influences on diet quality in older age: the importance of social factors. Age Ageing 2017;46:277-83. https://doi.org/10.1093/ageing/afw180.
XIII. Drewelies J, Wagner J, Tesch-Römer C, Heckhausen J, Gerstorf D. Perceived control across the second half of life: the role of physical health and social integration. Psychol Aging 2017;32: 76-92. https://doi.org/10.1037/pag0000143.

XIV. Cherry KE, Brown JS, Kim S, Jazwinski SM. Social factors and healthy aging: findings from the Louisiana healthy aging study (LHAS). Kinesiol Rev (Champaign) 2016;5:50-6. https://doi. org/10.1123/kr.2015-0052.

XV. Hallgren J, Fransson EI, Kåreholt I, Reynolds CA, Pedersen NL, Dahl Aslan AK. Factors associated with hospitalization risk among community living middle aged and older persons: results from the Swedish Adoption/Twin Study of Aging (SATSA). Arch Gerontol Geriatr 2016;66:102-8. https://doi.org/10.1016/j.archger.2016.05.005.

XVI. Howrey BT, Raji MA, Masel MM, Peek MK. Stability in cognitive function over 18 Years: prevalence and predictors among older Mexican Americans. Curr Alzheimer Res 2015;12: 614-21. https://doi.org/10.2174/1567205012666150701102947.

XVII. Latham K, Williams MM. Does neighborhood disorder predict recovery from mobility limitation? Findings from the health and retirement study. J Aging Health 2015;27:1415-42. https://doi. org/10.1177/0898264315584328.

XVIII. Zhang W, Feng Q, Liu L, Zhen Z. Social engagement and health: findings from the 2013 survey of the shanghai elderly life and opinion. Int J Aging Hum Dev 2015;80:332-56. https://doi.org/ 10.1177/0091415015603173. 